1 Cytotoxic activity of LCS-1 is not only due to inhibition of

2 SOD1

3

4

$5 \quad$ Running title

6 Trypanocidal activity of LCS-1

7

8

9 Authors

10 Dietmar Steverding, Yzobelle Barcelos

11

12

13

14

15 University of East Anglia, Norwich, United Kingdom

Affiliation

4 Bob Champion Research and Education Building, Norwich Medical School,

16

17

18

Correspondence

19 Dietmar Steverding

20 Bob Champion Research and Education Building

21 Norwich Medical School

22 University of East Anglia

23 Norwich Research Park

24 James Watson Road

25 Norwich NR4 7UQ

26 United Kingdom

27 Tel.: +44/1603/591291

28 d.steverding@uea.ac.uk 
ABSTRACT

31 Background The cytotoxic activity of the pyridazin-3-one derivative LCS-1 was previously suggested to be due to the inhibition of superoxide dismutase 1 (SOD1). However, no direct evidence was provided that LCS-1 inhibits SOD1 within cells. Methods In this study, we investigated the cytotoxic activity of LCS-1 against bloodstream forms of Trypanosoma brucei, a protozoan parasite that does not express copper/zinc-containing SOD1, but an iron-containing superoxide dismutase (FeSOD). Results At $250 \mu \mathrm{M}$, LCS-1 did not inhibit the activity of FeSOD in cell lysates of bloodstream forms of $T$. brucei, confirming that the compound is a specific inhibitor of

39 SOD1. However, LCS-1 displayed substantial trypanocidal activity with a minimum inhibitory concentration of $10 \mu \mathrm{M}$ and a half-maximal effective concentration of 1.36 $\mu \mathrm{M}$, indicating that the cytotoxic action of the compound cannot solely be due to 42 inhibition of SOD1.

43 Conclusion The results of this study is an important finding as it shows that LCS-1 has more than one cytotoxic mode of action. 
Introduction

The pyridazin-3-one derivative LCS-1 (4,5-dichloro-2-(3-methylphenyl)pyridazin-3one; Fig. 1) was previously identified in a high-throughput chemical screen as an inhibitor for human lung adenocarcinoma cells [1]. Subsequent analysis provided evidence that superoxide dismutase 1 (SOD1) might be the target for LCS-1 [2]. However, direct inhibition of SOD1 within the lung adenocarcinoma H358 cells was not shown. In addition, the half-maximal inhibitory concentration $\left(\mathrm{IC}_{50}\right)$ for the inhibition of purified SOD1 was found to be higher than the half-maximal effective concentration $\left(E_{50}\right)$ for the inhibition of the growth of $\mathrm{H} 358$ cells $(1.07 \mu \mathrm{M}$ versus $0.8 \mu \mathrm{M}[2])$. This is an indication that SOD1 is probably not the only target for LCS-1. Usually, an inhibitor has a much better potency to block the activity of an isolated enzyme than to affect the growth of cells $\left(\mathrm{IC}_{50}<\mathrm{EC}_{50}\right)$; the reasons for this are diverse. Firstly, pharmacokinetics/pharmacodynamics relationships may result in lower intracellular drug concentration. Secondly, the free efficacious drug concentration within a cell may be reduced due to nonspecific binding to intracellular proteins. Thirdly, even if the intracellular concentration of a drug is not influenced by pharmacokinetics, pharmacodynamics and nonspecific binding, and an enzyme target can be inhibited to $50 \%$ at the $\mathrm{IC}_{50}$ value, in most cases this would not lead to $50 \%$ growth inhibition, as the remaining active enzyme molecules are usually abundant enough to maintain the cellular functions. Consequently, enzyme inhibitors exert their cell growth inhibitory activity at a much higher concentration.

To investigate whether LCS-1 displays additional cytotoxic activity, we tested the compound for its ability to affect the growth of bloodstream forms of the protozoan parasite Trypanosoma brucei. In contrast to mammalian cells, T. brucei does not express a SOD1 (Cu/Zn-SOD) but a Fe-SOD [3]. As LCS-1 specifically inhibits SOD1 and not SOD2 (Mn-SOD) [2], and as SOD2 has a high degree of sequence and structure similarity with FeSOD [4], one would expect that LCS-1 should not inhibit FeSOD and therefore should not affect the growth of bloodstream forms of $T$. brucei. 
Materials and Methods

77

\section{Drugs and chemicals}

LCS-1, pyrogallol and resazurin sodium salt were purchased from Sigma-Aldrich (Gillingham, Dorset, UK).

\section{Cell culture}

Bloodstream forms of the $T$. brucei clone 427-221a were grown in Baltz medium supplemented with $16.7 \%$ heat-inactivated bovine serum as described previously [5]. The cultures were maintained at $37^{\circ} \mathrm{C}$ in a humidified atmosphere containing $5 \%$ carbon dioxide.

\section{SOD activity assay}

The activity of Fe-SOD in trypanosome cell extracts was determined indirectly by the inhibition of pyrogallol autoxidation as described previously $[5,6]$. After harvesting bloodstream form trypanosomes, the cells were washed three times with $\mathrm{PBS} / 1 \%$ glucose and lysed $\left(5 \times 10^{7}\right.$ cells $\left./ 100 \mathrm{~mL}\right)$ in $5 \mathrm{mM}$ Tris, $0.1 \mathrm{mM} \mathrm{Na} 4-E D T A, p H ~ 7.8$, $400 \mu \mathrm{M}$ PMSF on ice for $10 \mathrm{~min}$. To remove cell debris, the lysed cells were centrifuged at $16873 \mathrm{~g}$ for $5 \mathrm{~min}$. Then, to $100 \mu \mathrm{L}$ measuring buffer (100 mM Tris, $2 \mathrm{mM}$ EDTA, $\mathrm{pH}$ 8.0), $25.5 \mu \mathrm{L}$ water, $4.5 \mu \mathrm{L}$ DMSO (positive control) or $4.5 \mu \mathrm{L} 11.11 \mathrm{mM}$ LCS-1 dissolved in DMSO (test), $50 \mu \mathrm{L}$ cleared cell extract $\left(2.5 \times 10^{7}\right.$ cell equivalents) or 50 $\mu \mathrm{L}$ lysis buffer (negative controls) were pipetted into wells of a 96-well plate. The background absorbance was read on a microplate reader at $450 \mathrm{~nm}$. Then, $20 \mu \mathrm{L}$ of a $2 \mathrm{mM}$ pyrogallol solution in $1 \mathrm{mM} \mathrm{HCl}$ was added and the increase in absorbance at $450 \mathrm{~nm}$ was recorded every minute over a period of $20 \mathrm{~min}$. 
103 The cell growth inhibition assay was performed as described in [5]. In brief, trypanosomes were seeded in 96-well plates in a final volume of $200 \mu \mathrm{L}$ of Baltz medium containing various concentration of LCS-1 (tenfold dilutions from $10^{-4} \mathrm{M}$ to $10^{-}$ $\left.{ }^{9} \mathrm{M}\right)$ and $1 \%$ DMSO. Wells containing medium and 1\% DMSO served as controls. The initial cell density was $1 \times 10^{4}$ cells $/ \mathrm{mL}$. After $24 \mathrm{~h}$ incubation, $20 \mu \mathrm{L}$ of $0.5 \mathrm{mM}$ resazurin in PBS (sterile filtered) was added and the cells were incubated for a further $48 \mathrm{~h}$. Subsequently, the absorbance was read on a microplate reader using a test wavelength of $570 \mathrm{~nm}$ and a reference wavelength of $630 \mathrm{~nm}$. The $\mathrm{EC}_{50}$ value $(50 \%$ effective concentration, i.e., the concentration of a compound necessary to reduce the growth rate of cells by $50 \%$ to that of controls) was determined by linear interpolation. The MIC value (minimum inhibitory concentration, i.e., the concentration of the compound at which all cells were killed) was determined microscopically by inspecting each well thoroughly for the presence of motile trypanosomes.

Results

To confirm that LCS-1 is not an inhibitor of Fe-SOD, the effect of the compound on the activity of Fe-SOD in T. brucei cell lysates was determined using the pyrogallol autoxidation assay. As previously shown, this assay readily determines the activity and inhibition of Fe-SOD in cell extracts of bloodstream forms of T. brucei [6]. However, SOD activity tests have to be evaluated with care as test compounds can interfere with the assay as recently shown [5]. Therefore, we first established whether the compound LCS-1 adversely affected the autoxidation of pyrogallol. The presence of $250 \mu \mathrm{M}$ LCS-1 did not markedly influence the autoxidation rate of pyrogallol as measured by the increase in absorbance at $450 \mathrm{~nm}$ (Fig. 2a). The time-dependent increase of absorbance in the presence and absence of LCS-1 was found to be almost identical. Next, we measured the effect of LCS-1 on the Fe-SOD activity in 
trypanosome cell lysates. Results showed that the presence of $250 \mu \mathrm{M} \mathrm{LCS}-1$ did not abolish the ability of the cell lysate to inhibit the autoxidation of pyrogallol (Fig. 2a). The observed inhibition of the autoxidation of pyrogallol by the cell lysate in the presence of LCS-1 was indistinguishable to that of the control cell lysate. The slow increase in absorbance towards the end of the measurement period is due to the fact that the hydrogen peroxide produced by the dismutation of superoxide is an inhibitor of Fe-SOD $[3,6]$. Taken together, this result confirmed that LCS-1 does not inhibit the activity of Fe-SOD.

The trypanocidal activity of LCS-1 was determined with $T$. brucei bloodstream forms 427-221a using the resazurin assay [5]. The compound showed a dosedependent effect on the growth of trypanosomes with a MIC value of $10 \mu \mathrm{M}$ and an $E_{50}$ value of $1.36 \mu \mathrm{M}$ (Fig 2b). Notably, the $\mathrm{EC}_{50}$ value of LCS-1 for its trypanocidal activity against trypanosomes did not differ much from the $\mathrm{EC}_{50}$ value of the compound for its cytotoxic activity against lung adenocarcinoma $\mathrm{H} 358$ cells $(1.36 \mu \mathrm{M}$ (this study) vs $0.8 \mu \mathrm{M}[2])$. Based on the considerable trypanocidal activity it can be concluded that SOD1 is most likely not the main target of LCS-1. Consequently, it can also be reasoned that the cytotoxic action of LCS-1 observed for human $\mathrm{H} 358$ cells is probably not just due to inhibition of SOD1.

\section{Discussion}

Pyridazin-3-one derivatives represent one of the most active class of chemical compounds displaying a wide range of biological activity [7]. For example, substituted pyridazin-3-ones have been shown to be inhibitors of stearoyl-CoA desaturase, cyclooxygenase, acetylcholine esterase and aldose reductase [7]. In light of this it is interesting to point out two herbicide compounds, chloridazon (5-amino-4-chloro-2phenylpyridazin-3-one) and metflurazon (4-chloro-5-(dimethylamino)-2-[3(trifluoromethyl)phenyl]pyridazin-3-one), which have very similar structure to LCS-1 
(Fig. 1). Chloridazon has been shown to interact with cell membranes [8] while metflurazon was found to affect lipid biosynthesis [9]. As LCS-1 and both herbicides are 4-chloro-2-phenylpyridazin-3-one derivatives, it is reasonable to assume that the mode of action of LCS-1 is related to that of chloridazon and metflurazon. In this context, it is worth to mention a previous study, which reported that the mitochondria of breast cancer cells treated with LCS-1 showed increased fragmentation and dilated cristae [10]. Although the authors of the study suggested that the observed effect was due to inhibition of SOD1 by LCS-1, only indirect evidence for reduced SOD activity was provided (1.6-fold increase of mitochondrial superoxide levels) [10]. However, the observed collapse of the integrity of mitochondria could also be a direct result of an interaction of LCS-1 with the membranes of the organelles rather than due to elevated levels of superoxide. Furthermore, it is also possible that the mitochondrial fragmentation is the result of a combined effect of LCS-1. For example, increased superoxide levels could impair mitochondrial membranes so that they are more susceptible to direct damage by LCS-1 or vice versa. In any case, the exact mechanism of the cytotoxic activity of LCS-1 remains to be uncovered but this may be difficult because pyridazin-3-one derivatives have been shown to affect many cellular targets [7]. Based on the relative high lipophilicity of LCS-1, which is greater than that of chloridazon (LogP of LCS-1 $=2.85$; LogP of chloridazon $=1.14$ ), it is reasonable to assume that the compound may interact with cell membranes. This suggestion is supported by preliminary experiments. For example, incubation of bloodstream forms of $T$. brucei with LCS-1 caused fast lysis of the cells (Fig. 1S). In contrast, the trypanocidal drug suramin that inhibits especially trypanosomal glycolytic enzymes, did not cause any lysis of trypanosomes at the same concentration and incubation period (Fig. 1S). Likewise, incubation of human promyelocytic leukaemia HL-60 cells with LCS-1 resulted in fast cell lysis while the anti-cancer drug and proteasome inhibitor bortezomib did not under the same incubation conditions (Fig. 2S).

In conclusion, our results do not support the previous suggestion that LCS-1 exerts its cytotoxic activity solely through inhibition of SOD1. This finding is of major 
relevance for future studies, as it will help to avoid misinterpretation of research results obtained with LCS-1.

Conflict of interest

The authors declare no conflict of interests.

References

[1] Somwar R, Shum D, Djaballah $H$, Varmus $H$. Identification and preliminary characterization of novel small molecules that inhibit growth of human lung adenocarcinoma cells. J Biomol Screen 2009; 14: 1176-1184

[2] Somwar R, Erdjument-Bromage H, Larsson E, et al. Superoxide dismutase 1 (SOD1) is a target for a small molecule identified in a screen for inhibitors of the growth of lung adenocarcinoma cell lines. Proc Natl Acad Sci USA 2011; 108, $16375-16380$

[3] Kabiri M, Steverding D. Identification of a developmentally regulated iron superoxide dismutase in Trypanosoma brucei. Biochem J 2001; 360: 173-177

[4] Jackson SMJ, Cooper JB. An analysis of structural similarity in the iron and manganese superoxide dismutases based on known structures and sequences. BioMetals 1998; 11: 159-173

[5] Steverding D, Kolosevska K, Sánchez-Moreno M. Trypanocidal activity of tetradentated pyridine-based manganese complexes is not linked to inactivation of superoxide dismutase. Exp Parasitol 2018; 192: 1-5

[6] Steverding D, Scory S. Trypanosoma brucei: unexpected azide sensitivity of bloodstream forms. J Parasitol 2004; 90: 1188-1190

[7] Asif M. Various chemical and biological activities of pyridazinone derivatives. Cent Eur J Exp Bio 2017; 5: 1-19 
[8] Suwalsky M, Benites M, Villena $F$, et al. The organochlorine herbicide chloridazon interacts with cell membranes. Comp Biochem Physiol C Pharmacol Toxicol Endocrinol 1998; 120: 29-35

[9] Khan MU, Lem NW, Chandorkar KR, Williams JP. Effects of substituted pyridazinones (San 6706, San 9774, San 9785) on glycerollipids and their associated fatty acids in the leaves of Vicia faba and Hordeum vulgare. Plant Physiol 1979; 64: 300-305

[10] Papa L, Hahn M, Marsh EL, et al. SOD2 to SOD1 switch in breast cancer. J Biol Chem 2014; 289: 5412-5416

Figure legends

Fig. 1 Structures of LCS-1, and of the related compounds chloridazon and metflurazon. The PubChem Compound Identifier (CID) for each compound is also shown.

Fig. 2 Effect of LCS-1 on the activity of Fe-SOD in cell extract and on the growth of bloodstream form of T. brucei. (a) The activity of Fe-SOD in cleared trypanosome cell lysates was determined indirectly by the inhibition of pyrogallol autoxidation. To 180 $\mu \mathrm{L}$ mixture containing $2.5 \times 10^{7}$ cell equivalents and $50 \mathrm{nmol} \mathrm{LCS}-1$ (closed circles) or $2.5 \%$ DMSO alone (closed squares), $20 \mu \mathrm{L}$ of a $2 \mathrm{mM}$ pyrogallol solution in $1 \mathrm{mM} \mathrm{HCl}$ was added and the increase in absorbance at $450 \mathrm{~nm}$ was followed photometrically. Negative controls indicate the autoxidation of pyrogallol in the absence of cell lysate but in the presence of $50 \mathrm{nmol}$ LCS-1 (open circle) or 2.5\% DMSO alone (open squares). A representative result from two independent experiments is shown. (b) Trypanosomes were incubated with varying concentrations of LCS-1. After $72 \mathrm{~h}$ of culture, cell viability and proliferation was determined with the colorimetric dye resazurin. Mean values \pm SD of three experiments are shown. 
244 Fig. 1<smiles>Cc1cccc(-n2ncc(Cl)c(Cl)c2=O)c1</smiles>

LCS-1

245 CID: 779573<smiles>Nc1cnn(-c2ccccc2)c(=O)c1Cl</smiles>

chloridazon CID: 15546<smiles>CN(C)c1cnn(-c2cccc(C(F)(F)F)c2)c(=O)c1Cl</smiles>

metflurazon CID: 32011 
247

Fig. 2

249

250

251

252 a

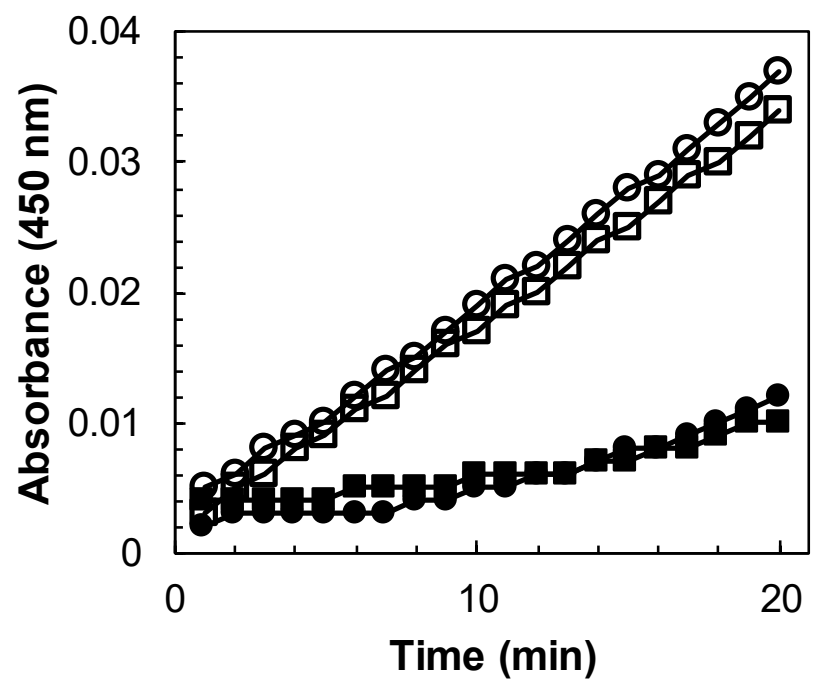

b

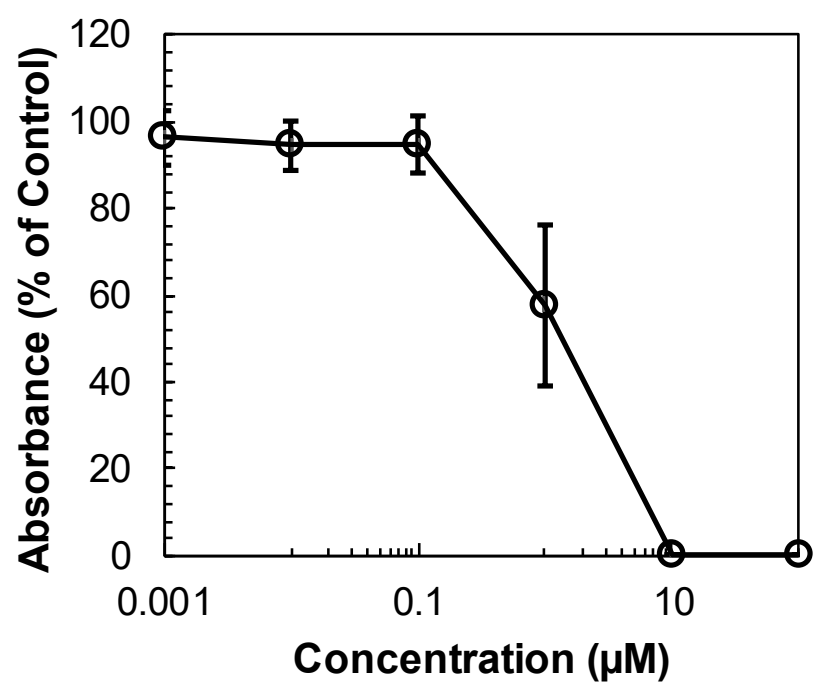



SOD1

\section{Authors}

Dietmar Steverding, Yzobelle Barcelos

262

\section{Affiliation}

Bob Champion Research and Education Building, Norwich Medical School, University of East Anglia, Norwich, United Kingdom

267

Correspondence

270

Dietmar Steverding

271 Bob Champion Research and Education Building

272 Norwich Medical School

273 University of East Anglia

274 Norwich Research Park

275 James Watson Road

$276 \quad$ Norwich NR4 7UQ

277 United Kingdom

278 Tel.: +44/1603/591291

279

d.steverding@uea.ac.uk 


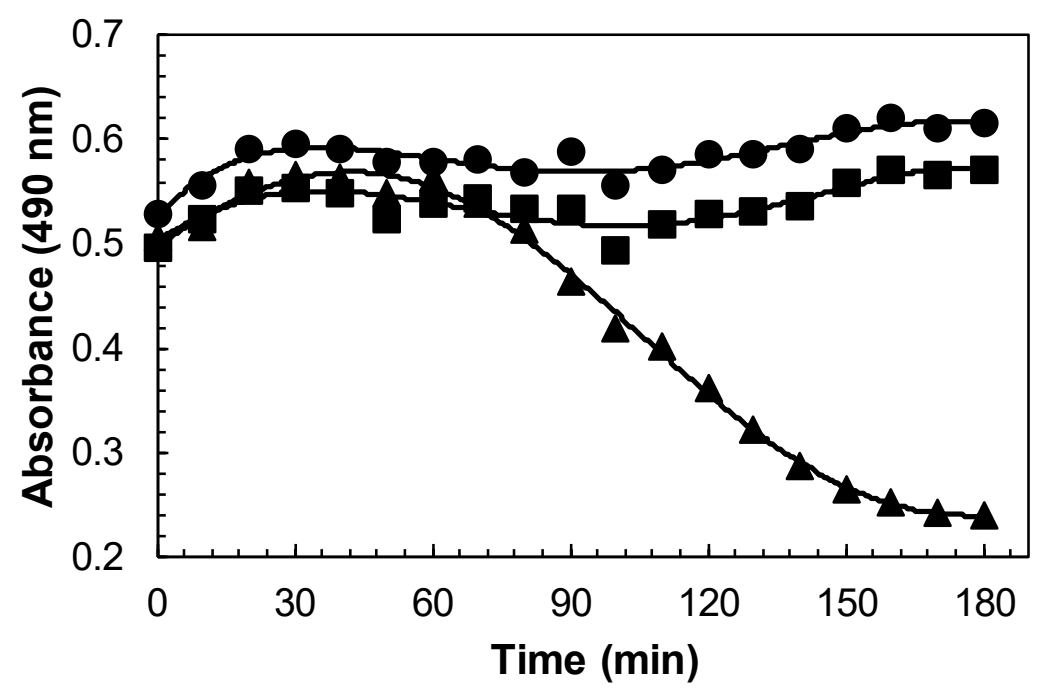

281

282

283 Fig. 1S Lytic effect of LCS-1 on bloodstream forms of Trypanosoma brucei. Lysis of trypanosomes was measured by light scattering at $490 \mathrm{~nm}$. Note that a decrease in absorbance corresponds to increasing lysis of cells. Bloodstream forms of T. brucei (5 $\times 10^{7} \mathrm{cell} / \mathrm{ml}$ ) were incubated with $100 \mu \mathrm{M}$ LCS-1 (triangles), $100 \mu \mathrm{M}$ suramin (squares) or DMSO (circles) in culture medium at $37{ }^{\circ} \mathrm{C}$ in a humidified atmosphere containing $5 \% \mathrm{CO}_{2}$. The final DMSO concentration was $1 \%$. Every $10 \mathrm{~min}$, the absorbance was measured over a period of $3 \mathrm{~h}$. After $1 \mathrm{~h}$ incubation, absorbance of the culture incubated with LCS-1 started to decrease indicating lysis of trypanosomes. After $3 \mathrm{~h}$ incubation, all trypanosomes were lysed. In contrast, cultures incubated with only DMSO or with the trypanocidal drug suramin showed no lysis of trypanosomes over the $3 \mathrm{~h}$ incubation period. A representative result from two independent experiments is shown. 


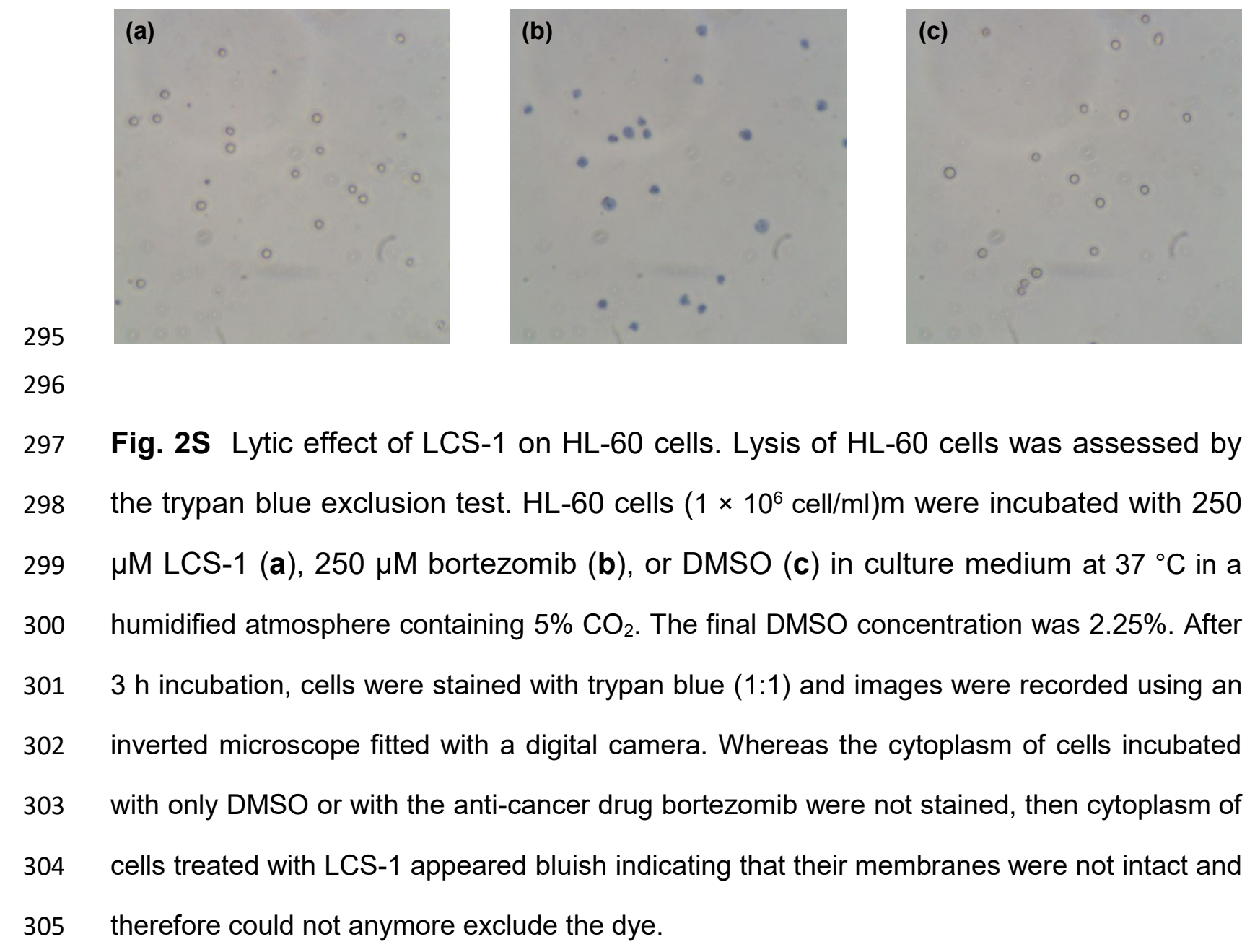

